\title{
Inclusive Schools:
}

\section{Re-defining the Concept of Student Leadership}

\section{Amy Cadman}

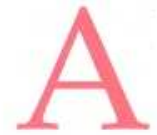

knot of students gathers by the 'smoking doors,'

intent on projecting an air of apathetic cool. Not far away, two younger girls, probably grade nines, watch the smokers strike poses of studied indifference, whispering excitedly. One girl seems eager to join the smokers; the other clearly thinks it's a bad idea. Temptation trumps loyalty, and the first girl steps hesitantly into the haze. She is given an icy once-over by the crowd, but welcomed into the fold once she pulls out a cigarette of her own and asks for a light. Her friend remains on the periphery, unsure of what to do. Eventually, she moves to join the group but turns down a proffered cigarette; the group turns its back on her and strides away as one, never looking back. The girl calls out to her retreating friend but is ignored; soon she is alone. She looks one last time towards the now-distant crowd, and her face is enveloped in darkness as the stage lights fade to black.

The lights rise along with a round of hearty applause, and the critique begins: overwhelmingly positive feedback on a strong scene, and few suggestions regarding timing and cues. The actors accept both accolades and advice gracefully, talk amongst themselves briefly, and jot some notes on their scripts. I look at my watch - still thirty minutes until the bell - and usher these students back to the audience so that another group can take the stage. This time, the scene is a humor- ous take on a ninth-grader's nightmarish first day of high school. Applause, critique, and then the mood turns darker as a girl is driven to the brink of suicide because she doesn't fit in. Pretty heavy stuff for a Monday morning, but there are no complaints. This is what students have come to expect, and to count upon, during Grade Twelve Drama at Brantford's North Park Collegiate and Vocational School (NPCVS).

No one enrolled is expecting an easy ride, but as a student teacher even I feel challenged by this course. During our pre-placement meeting, my associate teacher ${ }^{1}$ asks me if I am comfortable working with this class on a unit entitled 'Grade Nine Vignettes.' Students started this unit on the first day of the term, when they received the syllabus indicating that this unit was one of ADA4M's major projects. They formed groups of seven, and they learned that each group was responsible for writing four short scenes, employing a variety of dramatic techniques, focusing on the issues that grade eight students worry about as they anticipate their first year of high school. Before writing scenes, they conducted focus groups with grade nine students at NPCVS to learn what some of these fears had been, and how their anxieties had, or had not, proven founded when they reached NPCVS in September. With this research in hand, groups began crafting scenarios around the issues which struck them as most pertinent.

My placement began in February, and I worked with students on this unit until mid-March. The unit will culminate in early April, when grade eight classes from NPCVS's five feeder schools come to the North Park theatre to watch the 'Grade Nine Vignettes.' Following the performance the grade twelve students will lead a talk-back session with the audience, answering questions and providing further information about the issues raised in the play.

This is the second year that my associate teacher has run the Grade Nine Vignettes unit with her grade twelve class, and based on last year's outcome, it is highly beneficial for all involved: performers, audience, and NPCVS as a school. 'Grade Nine Vignettes' made it clear not only to students, but to the community, that NPCVS recognized the anxieties associated with beginning high school. Furthermore, the presentation demonstrated that not just administration and faculty, but students as well, were committed to making their school a more welcoming place for all.

The reason that this challenging unit is a success, and the reason that students gain so much from it, is that although it is very much tied to the Ministry Arts Curriculum, it not only meets but goes beyond the stated expectations for the course. 'Grade Nine Vignettes' covers key learning expectations through an approach that incorporates essential elements of Ontario's Student Success Strategy. In addition to building curriculum-specific skills, it develops skills essential to students' development as individuals beyond the classroom. Most significantly, 'Grade Nine Vignettes' demonstrates student 
leadership as an inclusive quality attainable by all, not a role which is the exclusive domain of the few with 'exceptional' abilities.

When thinking of what leadership means in a high school setting, stereotypical images inevitably come to mind: the highachieving class valedictorian; the

Part of being a leader is
undoubtedly setting an
example that others want
to follow, but this
example must be realistic
and attainable if it is to
inspire success rather
than promote feelings of
inadequacy.

athletically gifted football captain; the popular and committed student body president. There is nothing inherently wrong with such definitions of leadership, but they have obvious limitations. Ontario's Student Success Strategy is built on the premise that "ensuring every young person has the opportunity to succeed, to reach his or her full potential, is vital to building a stronger society." ${ }^{2}$ The above versions of success may represent the "full potential" of some students, but clearly there are countless other potentials which are no less meaningful for students to reach. In honouring a select number of students who embody this traditional vision of a leader - thanks to their own hard work, to be sure, but thanks also to genetics, socioeconomic status, and any number of other life factors - we cannot help but discredit the achievements of countless other students.

Many would argue that leadership becomes a meaningless term if in our efforts to build inclusive schools and promote student success we start lauding those who are not head-andshoulders above their peers. Conversely, I believe that the concept of leadership is already meaningless to the vast majority of our students whom its current definition does not describe. It is an accurate reflection of our cultural mores, I realize, yet it seems somehow cruel to seek out the strongest, smartest, prettiest, most talented, most popular, most 'perfect' students that we teach and hold them up as role models for everyone else to follow. The impact this has upon the chosen few merits its own discussion, but the impact that it has on legions of priceless - yet less 'perfect'- students is obvious. These students are alienated, and many, perhaps justifiably, feel like giving up. Perfection is difficult to identify with, so why would we imagine that students will be led to strive for it? Part of being a leader is undoubtedly setting an example that others want to follow, but this example must be realistic and attainable if it is to inspire success rather than promote feelings of inadequacy.

An internet search of "high school student leadership Canada" reveals two things: first, if you've spent your high school career as club president, newspaper editor, team captain, and volunteered as a little league coach and Scout troupe leader on the side, a plethora of post-secondary scholarships await you. Everyone - postsecondary institutions, private companies, community associations, and the government loves a student leader. Even the Canadian Association of Principals offers a Student Leadership award, with the following selection criteria: leadership in school activities, leadership in the community, academic achievement, candidate essay, and number of

\section{3:2 Spring/Summer 2006}

previous recognitions/awards/ scholarships won. ${ }^{3}$

This of course benefits students who are natural born leaders, yet excludes students who want to get involved but lack confidence and/or experience. In addition to the myriad of scholarships for those who already are student leaders, the search string turns up a large number of 'student leadership' camps, conferences, etc. logical places to learn key interpersonal skills and master poised self-assurance, right? Not necessarily. In many cases, student participants must have stellar marks, be able to pay high travel costs and program fees, and must already have a proven track record of school and/or community leadership. ${ }^{4}$ In other words, the students who might benefit the most from leadership training programs often don't qualify for enrollment. Surely this is an overly cynical generalisation, but many student leadership programs appear to have been created by leaders for leaders, offering networking opportunities, blocks of resume-building gold, and affirmation of one's own successes all in one convenient weekend package.

Where, then, does a happy middle ground in terms of student leadership lie? How can we reward excellence, while simultaneously acknowledging effort, and all the while give students something to aspire to? The august achievements which have traditionally defined student leadership are still worthy of recognition. It is essential, though; that we remember that achievement alone is not a harbinger of primacy. In presuming that exemplary accomplishments in a specific field translate automatically into 'leadership' in terms of the full high school experience, 


\section{3:2 Spring/Summer 2006}

we are missing the point. As impressive and worthy of accolades as major acts are, true leadership is often demonstrated by unremarkable, wonted behaviours. If a leader is someone in whom we can all see our best selves reflected, then a more realistic definition of student leadership can be found in the many minor reasons students earn our admiration, and that of their peers, every day. School culture is built out of the negligible actions and subtle encounters that take place as staff and students go about their days.

Positive school culture requires staff and students to discover the shared goals and values which unite them as a community. NPCVS is a large school, and its population is ethnically, racially, and socio-economically diverse. Students' varied backgrounds have endowed them with a wide range of abilities, beliefs, and aspirations for the future. Building a cohesive school culture is challenging in such a setting, but NPCVS is committed to helping students respect their differences, while also striving to find common ground.

In essence, recognition of this 'common ground' is what the Grade Nine Vignette unit is based on. It is essential that students not merely be told, but rather discover for themselves, that disparity does not necessarily rule out harmony, and this unit provides them with this opportunity.

As varied as students are, they share one common goal: to be accepted. When entering an unfamiliar environment, it is natural for many individuals to conform to the behaviours they presume will help them to fit in. There is enormous comfort in feeling as though one 'belongs,' and it is often easier to settle for acceptance as the self one is trying to project rather than maintain the confi- dence that one will be accepted as the person he or she truly is.

While exploring many different situations, the essential focus of all the vignettes is this desire for acceptance. The scenarios are never overtly didactic, and are not intended as a primer on how to succeed in high school; such an approach would be antithetical to the spirit of the play. The individual scenes which comprise the play do not provide answers, but are purposely left open-ended. The subtext of the performance is that high school, like the world beyond it, constantly presents one with both pressures and uncertainties, but also with choices.

In some of the scenes, the grade twelve students play roles which illustrate the difference that small gestures can make: being a friendly face for a new student by simply taking a moment to say ' $\mathrm{hi}$;' taking the time to talk to nervouslooking student and find out what he or she is worried about; deciding not to sacrifice one's own values for a quick fix of superficial acceptance.

Through the Grade Nine Vignettes unit, students became cognizant of the fact that it is not necessary to be the one delivering speeches at school assemblies or making an obvious and concrete contribution to the school community in order to be a leader. The most valuable characteristics of leadership are often demonstrated by students who take the time to do the little things that make their school a friendlier, more welcoming, and more comfortable place for everyone to be. Such students may not even know they are leading, but they are modeling the sort of behaviours which encourage their peers to also act in ways that make high school a positive and worthwhile experience for all.

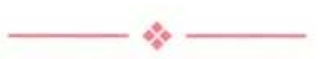

${ }^{1}$ Ms. Wendy McIsaac

2"Helping Students Succeed Instead of Dropping Out": News Release, Oct. 14, 2005. Dalton McGuinty - Premier of Ontario. Mar. 9, 2006. < http://www.premier.gov.on.ca> .

${ }^{3}<$ http://www.cdnprincipals.org >

${ }^{4}$ This by no means describes all leadership training programs aimed at Canadian high school students. Programs offered by the YMYWCA organisation, and the Duke of Edinburgh 'Young Canadian Challenge' are outstanding examples of inclusive, interest-based, highly accessible leadership opportunities for youth. The above-mentioned internet search, however, turned up many more programs with all or most of these restrictive eligibility requirements. Notable examples include "Leaders in Motion" (housed at a Tim Horton's Children's Foundation Camp in St. George, Ontario), the Polar Bears International Science Leadership Camp (held annually in Churchill, Manitoba, and allowing twelve students chosen from a pool of international applicants to participate in field work with leading scientists and speak to thousands of people as "Ambassadors of the Artic"), and the Canadian Student Leadership Conference (held annually since 1985; excerpt from 2006 program: "student and teacher leaders from across Canada celebrate Ordinary Youth Doing Extraordinary Things").

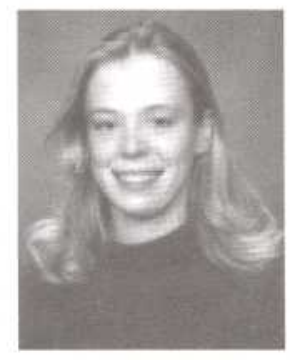

Amy Cadman M.A., B.ed. graduated in 2006 from Brock University's PreService Education Program. In addition to teaching English and Drama this year, Amy has previously worked with exceptional students and at-risk youth. Her direction of students in recent peer education/ social action theatre projects (the Sexual Assault Centre of BrantCrime Prevention Council of Canada's 'Youth Theatre Project'; the YMYWCA of Brantford-Department of Canadian Heritage's 'Multicultural Youth Theatre and Video Project') has led to her interest in the role that student leadership plays in education. 